\title{
Vertical Cooperative Advertising with Substitute Brands
}

\author{
You-Hua Chen and Xiao-Wei Wen \\ College of Economics \& Management, South China Agricultural University, Guangzhou 510642, China \\ Correspondence should be addressed to You-Hua Chen; chenyhua214@163.com
}

Received 11 July 2013; Accepted 24 August 2013

Academic Editor: X. Henry Wang

Copyright (C) 2013 Y.-H. Chen and X.-W. Wen. This is an open access article distributed under the Creative Commons Attribution License, which permits unrestricted use, distribution, and reproduction in any medium, provided the original work is properly cited.

Cooperative (co-op) advertising is attracting more and more attention. This paper analyzes co-op advertising behavior based on a dual-brand model with a single manufacturer and a single retailer, and some interesting conclusions are achieved. Firstly, the firm in the supply chain advertises both brands, and the difference of advertising expenditure is not very large in equilibrium. Secondly, the retailer's advertising and the manufacturer's participation ratios depend on both the retailer's and the manufacturer's marginal profits. Thirdly, the stimulating effect increases the advertising investment while the competition effect decreases it, but they have no effect on the manufacturer's participation ratio. Fourthly, co-op advertising is more sensitive to the manufacturer's marginal profits than those of the retailer. Lastly, total advertising investment and profit are greater under cooperative decision than under Stackelberg decision.

\section{Introduction}

Taking cooperative advertising as an example, the industrial firm becomes more dependent on its cooperative partners [1]. Co-op advertising is a practice in which the manufacturer pays his retailer some proportion of the expenditure of local advertising $[2,3]$. Co-op advertising is a type of cost-sharing contracts to promote sales. The original justification of co-op advertising is the existence of advertising spillover between firms in the vertical supply chain. More and more supply chains take part in co-op advertising and, co-op advertising is often used in consumer goods industries $[4,5]$. For example, Nagler [6] reported that the total co-op advertising expenditure doubled every two years from 900 million dollars in 1970 to 15 billion dollars in 2000. Based on Sen [7] and Dant and Berger [8], 25\%-40\% of the manufacturers, such as General Electric, Apple, and IBM Corporation, invest in coop advertising with their retailers.

In practice, the manufacturer with co-op advertising contributes at least $50 \%$ of the advertising expenditure. Berger [9] claimed that generally the cost-sharing proportion between manufacturer and retailer is 50\%-50\%. Brennan [10] identified that IBM Corporation bears $50 \%$ of the co-op advertising cost with its retailer, while Apple Corporation's participation ratio is 75\%. Bergen and John [11] showed that household appliances manufacturers pay $70 \%$ of the co-op advertising expenditure to their retailers.

Berger [9] initially addressed co-op advertising using a mathematical method. Subsequently, many people discussed it from different perspectives [2, 3, 5, 12-15]. Yue et al. [16], Xie and Wei [3], He et al. [17], and Viscolani [18] employed the dynamic model while Chintagunta and Jain [19], Jørgensen et al. [2], and Jørgensen et al. [20] used the static model to investigate co-op advertising. (Dynamic model has an advantage in analyzing long-term effect of advertising while static model makes it easy to study how the variation of parameter affects the equilibrium solution.) Based on Nerlove and Arrow's [21] goodwill model, Jørgensen et al. [2] and Jørgensen et al. [20] examined the phenomenon that consumer goods producers prefer to launch co-op advertising with their retailers. They classified advertising into short-term advertising and long-term advertising. Longterm advertising affects the goodwill, while short-term advertising only induces local sales. Huang and Li $[4,5]$ argued that manufacturers spend on both co-op advertising and brand name investment, but co-op advertising investment diminishes brand name expenditure. Both retailer's advertising expenditure and manufacturer's participation ratios are 
affected by their marginal profits. In co-op advertising, a manufacturer always dominates a retailer, but Huang et al. [5] declared that the retailer's market power is becoming stronger and stronger.

Karray and Zaccour [12] discussed co-op advertising with multiple products. (The retailer sells both the manufacturer's goods and its own brands. For example, Wal-Mart sells selfowned property brands, such as Great Value, Mainstays, and Simply Basic as well as other manufacturers' products.) In their study, a retailer is a collaborator as well as a competitor to the manufacturer, and the retailer's private brands hurt the manufacturer's profits. Interestingly, Alston et al. [22] addressed horizontal co-op advertising between beef market and pork market and declared that the beggar-thyneighbor effect (beggar-thy-neighbor effect is implicit when a substantial part of the benefits to the producers authorizing the program comes at the expense of the producers of competing commodities [22]) lowers advertising expenditure while co-op advertising increases profits. By employing the competition effect, (since there are two retailers in the supply chain, the competition between the two retailers affects the manufacturer's strategy) Wang et al. [14] extended coop advertising behavior to one-manufacturer two-retailer system. In their model, the manufacturer invests both in local advertising and in national brand name advertising, but national brand name advertising reduces local advertising, and the manufacturer does not always support the retailer's local advertising. Zhang and Xie [15] claimed that national brand name advertising increases as the number of retailers increase, while Xie and Wei [3] declared that most of the prior studies assumed sales to be only affected by advertising and ignored the price. But in their research, they found that co-op advertising decreases product price and increases consumer welfare. Xie and Neyret [23] and He et al. [24] also employed a price model to investigate supply chain co-op advertising activity.

In summary, most of existent papers used single-manufacturer single-retailer single-brand or single-manufacturer dual-retailers single-brand model, and few of them considered the situation that the supply chain supplies dual/multiple substitute brands. But it is common for one manufacturer to produce two or more substitute brands simultaneously. (Procter \& Gamble produces several kinds of shampoos, such as Rejoice, Head \& Shoulders, Pantene, and Sassoon.) Stimulated by this phenomenon, this paper employs a dualbrand model with a single manufacturer and a single retailer to study co-op advertising and reaches some interesting conclusions. (It is easy to be expended to multiple-brand case). Assuming that the manufacturer supplies two substitute. (The substitute relationship of the two brands is reflected by the competition effect of co-op advertising, which means that the increase in advertising of one brand decreases the sales of the other brand) brands and launches co-op advertising with the retailer and co-op advertising has both the stimulating effect and the competition effect, (the stimulating effect means that co-op advertising increases the sale of the advertised brand, while the competition effect the implies advertising decreases the sale of the substitute brand) this study obtains the following conclusions. Firstly, co-op advertising promotes both the profit of the manufacturer and the profit of the retailer, but the gap between the advertising expenditure of different brands is smaller than a certain amount. Secondly, marginal profits of the manufacturer are more than half of the marginal profits of the retailer, or else the manufacturer has no incentive to share any advertising expenditure with its retailer. Besides, the stimulating effect promotes advertising while the competition effect inhibits it. Co-op advertising increases with the marginal profits of the manufacturer and the retailer, but it is more sensitive to the manufacturer's marginal profit than the retailer's. More interestingly, the participation ratio of the manufacturer has nothing to do with those effects of advertising. Finally, profits of both participants are higher in the cooperative situation than in the Stackelberg case.

The rest of this paper proceeds as follows. The basic model and assumptions are presented in the next section. The model is analyzed in Section 3, under both cooperative situation and Stackelberg situation. Then some concluding remarks are given in the last section.

\section{Model and Assumptions}

Assume that there are one manufacturer and one retailer in the supply chain, and they supply two substitute brands, denoted to brand $i(i=1,2)$ simultaneously. (The substitute of the two brands is represented by the competition effect of co-op advertising.) Advertising has two effects: stimulating effect and competition effect. The stimulating effect is the positive effect of co-op advertising, which means that advertising motivates the sales of the advertised brand while the competition effect is the negative effect of co-op advertising, which indicates advertising for one brand inhibits the sales of the other. The retailer determines that the co-op advertising expenditure while the manufacturer decides its best participation ratio. (This is a general assumption, and almost all other studies propose that assumption.) Then, a dual-brand model with a single manufacturer and a single retailer is established as follows.

The manufacturer solves the following problem:

$$
\begin{aligned}
\operatorname{Max}_{t_{1}, t_{2}} \pi_{M}= & \rho_{M_{1}}\left(z_{1}+\sigma \sqrt{a_{1}}-\delta \sqrt{a_{2}}\right) \\
& +\rho_{M_{2}}\left(z_{2}+\sigma \sqrt{a_{2}}-\delta \sqrt{a_{1}}\right)-t_{1} a_{1}-t_{2} a_{2},
\end{aligned}
$$

while the retailer solves the following problem:

$$
\begin{aligned}
\operatorname{Max}_{a_{1}, a_{2}} \pi_{R}= & \rho_{R_{1}}\left(z_{1}+\sigma \sqrt{a_{1}}-\delta \sqrt{a_{2}}\right)+\rho_{R_{2}}\left(z_{2}+\sigma \sqrt{a_{2}}-\delta \sqrt{a_{1}}\right) \\
& -\left(1-t_{1}\right) a_{1}-\left(1-t_{2}\right) a_{2} .
\end{aligned}
$$

$z$ is a positive constant that represents the minimum sales of brand $i(i=1,2)$; without loss of generality, this paper assumes $z_{1}=z_{2}=z$. (Minimum sale is the sale without advertising. And $z_{i}(i=1,2)$ has nothing to do with the equilibrium solutions, so we assume $z_{i}=z_{j}=z$.) $\pi_{M}$ and $\pi_{R}$ are the total profits of the manufacturer and the retailer, respectively; $\rho_{M_{i}}$ and $\rho_{R_{i}}(i=1,2)$ represent 
the marginal profits of the manufacturer and the retailer; $a_{i}, t_{i}(i=1,2)$ are co-op advertising expenditure of the retailer and participation ratio of the manufacturer. $\sigma$ is the stimulating effect parameter of advertising, while $\delta$ denotes the competition effect parameter. $\sigma=\delta$ means that the advertising impacts on the two brands are exactly the same, and $\sigma \neq \delta$ implies that the advertising impacts on the two brands are different. Before analyzing the model, this paper puts forward the following assumptions.

\subsection{Assumptions. We have the following assumptions:}

(i) $\sigma>\delta$,

(ii) $\rho_{M_{1}} \approx \rho_{M_{2}}, \rho_{R_{1}} \approx \rho_{R_{2}}$,

(iii) $\rho_{R_{1}} \sigma-\rho_{R_{2}} \delta>0, \rho_{M_{1}} \sigma-\rho_{M_{2}} \delta>0$.

Assumption (i) means that the stimulating effect is stronger than the competition effect and the advertising impacts on the two brands are difference. Assumption (ii) illustrates that the marginal profits different of the manufacturer (retailer) should not be too large. Combining assumptions (i) and (ii) yields assumption (iii). Furthermore, $\rho_{M_{1}} \sigma-\rho_{M_{2}} \delta$ and $\rho_{R_{1}} \sigma-\rho_{R_{2}} \delta$ are the net effect involved by co-op advertising on the profits of the manufacturer and the retailer.

\section{Model Analysis and Main Results}

Many firms supply products without advertising, which means that it is not essential for firms in the supply chain to launch co-op advertising for both brands. Indeed, we reach Proposition 1.

Proposition 1. If the sale of brand 2 (or 1) is more than zero even without advertising, advertising expenditure for brand 1 (or 2) should be no more than $z^{2} / \delta^{2}$ or $a_{i} \leq z^{2} / \delta^{2}$.

Proof. When $a_{2}=0$, the profit from brand 2 is $\pi_{R_{2}}=\rho_{R_{2}}(z-$ $\left.\sigma \sqrt{a_{1}}\right)$. If $\pi_{R_{2}} \geq 0$, then $z-\sigma \sqrt{a_{1}} \geq 0$ or $a_{1} \leq z^{2} / \delta^{2}$. For the same reason we have $a_{2} \leq z^{2} / \delta^{2}$. The proof is complete.

Proposition 1 implies that the difference of advertising expenditure between different brands should not be too large. If the supply chain only advertises one brand, the total advertising expenditure should be limited to a certain range, $\left[0, z^{2} / \delta^{2}\right]$. Otherwise, the profit from the brand without advertising is negative and the supply chain will not supply it. This successfully explains why advertising times and frequencies of Procter \& Gamble for different shampoos, such as Rejoice and Head \& Shoulders, are almost the same.

Proposition 2. The profit functions of the manufacturer and the retailer are concave.

Proof. See the appendix.

Proposition 2 makes sure that functions (1) and (2) have unique optimal solutions. Usually, the manufacturer in the supply chain is dominant over the retailer $[3,12,13,15]$. But as the power of the retailer increases, it acts as a cooperator to the manufacturer sometimes [5]. Accordingly, the model is analyzed henceforth under both the Stackelberg (leaderfollower) situation and the cooperative situation.

3.1. Stackelberg Situation. In the Stackelberg situation, the manufacturer acts as the leader and the retailer acts as the follower. The two firms in the supply chain play a two-stage Stackelberg game. The manufacturer decides its participation ratio in the first stage. Then, given the participation ratio, the retailer decides its best advertising expenditure in the second stage. To get the Stackelberg equilibrium solution, backward induction method is introduced, which means that we should solve the reaction function of the retailer in the second stage first. So solving function (2), we get

$$
\begin{aligned}
& a_{1}^{*}=\left(\frac{\rho_{R_{1}} \sigma-\rho_{R_{2}} \delta}{2\left(1-t_{1}\right)}\right)^{2}, \\
& a_{2}^{*}=\left(\frac{\rho_{R_{2}} \sigma-\rho_{R_{1}} \delta}{2\left(1-t_{2}\right)}\right)^{2} .
\end{aligned}
$$

Substituting (3)-(4) into (1) yields the following solutions, which are the best participation ratios of the manufacturer:

$$
\begin{aligned}
& t_{1}^{*}=1-\frac{2\left(\rho_{R_{1}} \sigma-\rho_{R_{2}} \delta\right)}{2\left(\rho_{M_{1}} \sigma-\rho_{M_{2}} \delta\right)+\left(\rho_{R_{1}} \sigma-\rho_{R_{2}} \delta\right)}, \\
& t_{2}^{*}=1-\frac{2\left(\rho_{R_{2}} \sigma-\rho_{R_{1}} \delta\right)}{2\left(\rho_{M_{2}} \sigma-\rho_{M_{1}} \delta\right)+\left(\rho_{R_{2}} \sigma-\rho_{R_{1}} \delta\right)} .
\end{aligned}
$$

From (5)-(6), we achieve Propositions 3 and 4.

Proposition 3. (i) The theoretical condition for the manufacturer to participate in co-op advertising is $\left(\rho_{M_{i}} \sigma-\right.$ $\left.\rho_{M_{j}} \delta\right) /\left(\rho_{R_{i}} \sigma-\rho_{R_{j}} \delta\right)>1 / 2,(i, j=1,2, i \neq j)$, and (ii) the empirical condition for the manufacturer to participate in coop advertising is $\left(\rho_{M_{i}} \sigma-\rho_{M_{j}} \delta\right) /\left(\rho_{R_{i}} \sigma-\rho_{R_{j}} \delta\right)>3 / 2$.

Proof. See the appendix.

We call $\left(\rho_{M_{i}} \sigma-\rho_{M_{j}} \delta\right) /\left(\rho_{R_{i}} \sigma-\rho_{R_{j}} \delta\right)>1 / 2$ the theoretical condition because it only exists in theory. $\left(\left(\rho_{M_{i}} \sigma-\right.\right.$ $\left.\rho_{M_{j}} \delta\right) /\left(\rho_{R_{i}} \sigma-\rho_{R_{j}} \delta\right)>1 / 2$ is equivalent to $t_{i}>0$.) In fact, the manufacturer's participation ratio is always equal to or more than 1/2 [9, 10] (Bergen and John, 1997). If $t_{i}>1 / 2$, then $\left(\rho_{M_{i}} \sigma-\rho_{M_{j}} \delta\right) /\left(\rho_{R_{i}} \sigma-\rho_{R_{j}} \delta\right)>3 / 2$. So $\left(\rho_{M_{i}} \sigma-\rho_{M_{j}} \delta\right) /\left(\rho_{R_{i}} \sigma-\right.$ $\left.\rho_{R_{j}} \delta\right)>3 / 2$ is called the empirical condition. $\left(\left(\rho_{M_{i}} \sigma-\right.\right.$ $\left.\rho_{M_{j}} \delta\right) /\left(\rho_{R_{i}} \sigma-\rho_{R_{j}} \delta\right)>3 / 2$ is equivalent to $t_{i}>1 / 2$.) By $\rho_{M_{1}} \approx \rho_{M_{2}}, \rho_{R_{1}} \approx \rho_{R_{2}}$, the theoretical condition is rewritten as $\rho_{M} / \rho_{R}>1 / 2$, which means that the marginal profit of the manufacturer should be at least $1 / 2$ of the retailer's. Otherwise, the manufacturer has no incentive to take part in co-op advertising. And the empirical condition becomes $\rho_{M} / \rho_{R}>3 / 2$, which illustrates that the manufacturer has more power than the retailer. (If $\rho_{M}>\rho_{R}$, the manufacturer can merge with the retailer to maximize its combined profit.) 
Proposition 4. (i) $t_{i}$ increases as $\rho_{M_{i}}$ increases and decreases as $\rho_{M_{j}}$ increases, (ii) $t_{i}$ increases as $\rho_{R_{j}}$ increases and decreases as $\rho_{R_{i}}$ increases, and (iii) $t_{i}$ is independent of $\sigma$ and $\delta,(i, j=$ $1,2, i \neq j)$.

Proof. See the appendix.

Proposition 4 demonstrates that the participation ratio of the manufacturer is affected by the marginal profits of its own as well as the retailer's. Interestingly, the participation ratio of the manufacturer has nothing to do with co-op advertising effects. The reason for this is that, as the leader of the supply chain, the manufacturer's strategic action is independent of the behavior of the retailer, which means that the manufacturer's participation ratio does not depend on the retailer's advertising expenditure. So it is also independent of the effects of advertising.

Given the best participation ratio $t_{i},(i=1,2)$, it is easy to get the rational co-op advertising expenditure of the retailer at the second stage. So substituting $t_{i}$ in (3) and (4) with (5)-(6), we reach the final expressions of $a_{i}^{*},(i=1,2)$ and achieve Propositions 5 and 6:

$$
\begin{aligned}
& a_{1}^{*}=\frac{1}{16}\left[2\left(\rho_{M_{1}} \sigma-\rho_{M_{2}} \delta\right)+\left(\rho_{R_{1}} \sigma-\rho_{R_{2}} \delta\right)\right]^{2}, \\
& a_{2}^{*}=\frac{1}{16}\left[2\left(\rho_{M_{2}} \sigma-\rho_{M_{1}} \delta\right)+\left(\rho_{R_{2}} \sigma-\rho_{R_{1}} \delta\right)\right]^{2} .
\end{aligned}
$$

Proposition 5. (i) $a_{i}^{*}$ increases (decreases) as $\rho_{M_{i}}\left(\rho_{M_{j}}\right)$ increases, (ii) $a_{i}^{*}$ increases (decreases) as $\rho_{R_{i}}\left(\rho_{R_{j}}\right)$ increases, (iii) $a_{i}^{*}$ increases (decreases) as $\sigma(\delta)$ increases, and (iv) $a_{i}^{*}$ increases as $t_{i}$ increases, $(i, j=1,2, j \neq j)$.

Proof. See the appendix.

Comparing with Proposition 4, the retailer's co-op advertising expenditure is also determined by the marginal profits of the retailer as well as those of the manufacturer. But $a_{i}^{*}$ decreases when $\rho_{M_{2}}$ and $\rho_{R_{2}}$ increase, while $t_{i}$ decreases as $\rho_{M_{2}}$ and $\rho_{R_{1}}$ increase. Furthermore, co-op advertising expenditure is also affected by the stimulating effect and the competition effect of advertising.

By Propositions 4 and 5, we find that the effects of advertising (including the stimulating effect and the competition effect) only affect the co-op advertising expenditure of the retailer but have no effect on the manufacturer's equilibrium participation ratio decision. Advertising has a spillover effect on the supply chain firms' profits, and the retailer acts as a cooperator as well as a competitor to the manufacturer. Besides, the difference in marginal profits between the manufacturer and the retailer should not be too large.

Proposition 6. Consider the following $\partial a_{1} / \partial \rho_{M_{1}}>\partial a_{1} / \partial \rho_{R_{1}}$, $\left|\partial a_{1} / \partial \rho_{M_{2}}\right|>\left|\partial a_{1} / \partial \rho_{R_{2}}\right|$.

Proof. Following the proof of Proposition 5, it is easy to achieve $\partial a_{1} / \partial \rho_{M_{1}}=2 \partial a_{1} / \partial \rho_{R_{1}}$ and $\partial a_{1} / \partial \rho_{M_{2}}=-2 \partial a_{1} / \partial \rho_{R_{2}}$, which means $\partial a_{1} / \partial \rho_{M_{1}}>\partial a_{1} / \partial \rho_{R_{1}},\left|\partial a_{1} / \partial \rho_{M_{2}}\right|>\left|\partial a_{1} / \partial \rho_{R_{2}}\right|$.

The proof of Proposition 6 is complete.
Proposition 6 indicates that, compared with the retailer's, the manufacturer's marginal profit effects on advertising expenditure are stronger, which means that co-op advertising is more sensitive to the marginal profits of the manufacturer. Considering that $\sigma>\delta$, both the net marginal profit effect of the manufacturer and that of the retailer on advertising are positive, and the manufacturer's net positive marginal profit effect on advertising is larger than the retailer's. In other words, the manufacturer in the supply chain has more incentive to expend on advertising, which provides an explanation for why manufacturers' participation ratios are always higher than $50 \%$.

Total profits of the manufacturer and the retailer are denoted as $\pi_{M}^{B}$ and $\pi_{R}^{B}$, respectively, if the supply chain advertises for both brands, $\pi_{M}^{S}$ and $\pi_{R}^{S}$ if it advertises for only one brand, and $\pi_{M}^{N}$ and $\pi_{R}^{N}$ if it advertises for none. Then, we acquire Proposition 7.

Proposition 7. The profits of the manufacturer and the retailer under different conditions satisfy the following relationships: $\pi_{M}^{B}>\pi_{M}^{S}>\pi_{M}^{N}$ and $\pi_{R}^{B}>\pi_{R}^{S}>\pi_{R}^{N}$.

Proof. See the appendix.

Advertising increases the profits of both the manufacturer and the retailer. So if the firms in the supply chain have no cash flow constraint, they always advertise for all their brands. We can find evidence in the reality. For example, Procter \& Gamble always advertises all of its shampoo brands, such as Rejoice, Head \& Shoulders, Pantene, and Sassoon, and all detergent brands, such as Tide, Lenor, and Ariel, at the same time.

3.2. Cooperative Situation. Many researches $[4,5,14]$ claim that market power of superretailers, such as Wal-Mart, Carrefour, Suning, and Gome (Suning and Gome are the two biggest household appliance retailers in China), becomes stronger and stronger and they become the strategic partner of manufacturer. So, in this part, we analyze co-op advertising under the cooperative situation.

And the maximization problem for the supply chain under the cooperation situation is

$$
\begin{aligned}
\operatorname{Max}_{a_{1}, a_{2}} \bar{\Pi}= & \pi_{M}+\pi_{R}=\left(\rho_{M_{1}}+\rho_{R_{1}}\right)\left(z+\sigma \sqrt{a_{1}}-\delta \sqrt{a_{2}}\right) \\
& +\left(\rho_{M_{2}}+\rho_{R_{2}}\right)\left(z+\sigma \sqrt{a_{2}}-\delta \sqrt{a_{1}}\right)-a_{1}-a_{2} .
\end{aligned}
$$

The optimal equilibrium solutions are

$$
\begin{aligned}
& \bar{a}_{1}=\frac{1}{4}\left[\left(\rho_{M_{1}}+\rho_{R_{1}}\right) \sigma-\left(\rho_{M_{2}}+\rho_{R_{2}}\right) \delta\right]^{2}, \\
& \bar{a}_{2}=\frac{1}{4}\left[\left(\rho_{M_{2}}+\rho_{R_{2}}\right) \sigma-\left(\rho_{M_{1}}+\rho_{R_{1}}\right) \delta\right]^{2} .
\end{aligned}
$$

The total profit of the manufacturer and the retailer under the Stackelberg situation is presented as follows:

$$
\begin{aligned}
\Pi^{*}= & \pi_{M}^{*}+\pi_{R}^{*}=\left(\rho_{M_{1}}+\rho_{R_{1}}\right)\left(z+\sigma \sqrt{a_{1}^{*}}-\delta \sqrt{a_{2}^{*}}\right) \\
& +\left(\rho_{M_{2}}+\rho_{R_{2}}\right)\left(z+\sigma \sqrt{a_{2}^{*}}-\delta \sqrt{a_{1}^{*}}\right)-a_{1}^{*}-a_{2}^{*} .
\end{aligned}
$$

Then, this study achieves Proposition 8. 
Proposition 8. $\bar{a}_{i}>a_{i}^{*},(i, j=1,2, i \neq j)$, and $\bar{\Pi}>\Pi^{*}$.

Proof. See the appendix.

Proposition 8 illustrates that the co-op advertising expenditure and the total profits under the cooperative situation are all more than those under the Stackelbreg situation. These conclusions are in accord with other investigations $[5,9,16$, 18]. More importantly, although the condition analyzed and the base model employed in this study are different from in other papers, we achieve the same conclusions as others, which means that the conclusions of Proposition 8 are robust. Proposition 8 also shows us that if the retail price of the retailer is fixed, cooperative decision heightens the social welfare.

\section{Concluding Remarks}

Advertising has strong spillover effect, and firms in the supply chain cannot acquire all the profits brought by advertising. So, more and more supply chain firms choose co-op advertising to improve sales. Stimulated by these phenomena, this paper employs a single-manufacturer single-retailer two-brand model to address co-op advertising. Different from other studies, this paper considers the phenomenon that the supply chain supplies two substitute brands simultaneously. Besides, this paper separates advertising effects into stimulating effect and competition effect.

This paper achieves several interesting conclusions. Firstly, if the supply chain firms supply two (or multiple) substitute brands, the difference of total expenditure between the two (or multiple) brands should not be too large. Secondly, cooperative (co-op) advertising increases the total supply chain profits and advertising expenditure. More interestingly, although both the stimulating effect and the competition effect affect the retailer's advertising decision, they have no effect on the manufacturer's participation ratio decision. The manufacturer' marginal profit as well as the retailer's marginal profit affects both the manufacturer's and the retailer's behavior. Moreover, the manufacturer's marginal profit has more effect on the supply chain decision than the retailer's. The stimulating effect increases co-op advertising while the competition effect decreases co-op advertising.

Next, the study can extend to multiple brands or considers the effect of capital market, such as debt financing behavior, which will also complicate the analysis. These are our further studies.

\section{Appendix}

Proof of Proposition 2. The first- and second-order optimal conditions of (1) and (2) yield

$$
\begin{array}{r}
\frac{\partial \pi_{R}}{\partial a_{i}}=\frac{1}{2}\left(\rho_{R_{i}} \sigma-\rho_{R_{j}} \delta\right)\left(a_{i}\right)^{-1 / 2}-\left(1-t_{i}\right), \\
(i, j=1,2, i \neq j),
\end{array}
$$

$$
\begin{gathered}
\frac{\partial^{2} \pi_{M}}{\partial a_{i}^{2}}=-\frac{1}{4}\left(\rho_{R_{i}} \sigma-\rho_{R_{j}} \delta\right)\left(a_{i}\right)^{-3 / 2} \\
<0, \quad \rho_{R_{i}} \sigma-\rho_{R_{j}} \delta>0 .
\end{gathered}
$$

Besides, we have $\partial^{2} \pi_{R} / \partial t_{1} \partial t_{2}=0$, so function (2) is concave. Solving $\partial \pi_{R} / \partial a_{i}=0$, we obtain

$$
\begin{aligned}
& a_{1}^{*}=\left(\frac{\rho_{R_{1}} \sigma-\rho_{R_{2}} \delta}{2\left(1-t_{1}\right)}\right)^{2}, \\
& a_{2}^{*}=\left(\frac{\rho_{R_{2}} \sigma-\rho_{R_{1}} \delta}{2\left(1-t_{2}\right)}\right)^{2} .
\end{aligned}
$$

Substituting (A.2) into function (1), we have

$$
\begin{aligned}
\pi_{M}= & \rho_{M_{i}}\left(z+\sigma \frac{\left(\rho_{R_{i}} \sigma-\rho_{R_{j}} \delta\right)}{2\left(1-t_{i}\right)}-\delta \frac{\left(\rho_{R_{j}} \sigma-\rho_{R_{j}} \delta\right)}{2\left(1-t_{j}\right)}\right) \\
& -t_{i}\left(\frac{\left(\rho_{R_{i}} \sigma-\rho_{R_{j}} \delta\right)}{2\left(1-t_{i}\right)}\right)^{2} \\
& +\rho_{M_{j}}\left(z+\sigma \frac{\left(\rho_{R_{j}} \sigma-\rho_{R_{j}} \delta\right)}{2\left(1-t_{j}\right)}-\delta \frac{\left(\rho_{R_{i}} \sigma-\rho_{R_{j}} \delta\right)}{2\left(1-t_{i}\right)}\right) \\
& -t_{j}\left(\frac{\left(\rho_{R_{j}} \sigma-\rho_{R_{j}} \delta\right)}{2\left(1-t_{j}\right)}\right)^{2} .
\end{aligned}
$$

So,

$$
\begin{aligned}
\frac{\partial \pi_{M}}{\partial t_{i}}= & \frac{\left(\rho_{M_{i}} \sigma-\rho_{M_{j}} \delta\right)\left(\rho_{R_{i}} \sigma-\rho_{R_{j}} \delta\right)}{2\left(1-t_{i}\right)^{2}} \\
& -\left(\frac{\left(\rho_{R_{i}} \sigma-\rho_{R_{j}} \delta\right)}{2\left(1-t_{i}\right)}\right)^{2} \\
& -t_{i} \frac{\left(\rho_{R_{i}} \sigma-\rho_{R_{j}} \delta\right)^{2}}{2\left(1-t_{i}\right)^{3}}
\end{aligned}
$$

$$
\begin{aligned}
\frac{\partial^{2} \pi_{M}}{\partial t_{i}^{2}}= & \frac{\left(\rho_{M_{i}} \sigma-\rho_{M_{j}} \delta\right)\left(\rho_{R_{i}} \sigma-\rho_{R_{j}} \delta\right)}{\left(1-t_{i}\right)^{3}}-\frac{\left[\left(\rho_{R_{i}} \sigma-\rho_{R_{j}} \delta\right)\right]^{2}}{\left(1-t_{i}\right)^{3}} \\
& -t_{i} \frac{3\left[\left(\rho_{R_{i}} \sigma-\rho_{R_{j}} \delta\right)\right]^{2}}{2\left(1-t_{i}\right)^{3}}
\end{aligned}
$$




$$
\begin{aligned}
& =\frac{1}{\left(1-t_{i}\right)}\left\{\frac{\left(\rho_{M_{i}} \sigma-\rho_{M_{j}} \delta\right)\left(\rho_{R_{i}} \sigma-\rho_{R_{j}} \delta\right)}{2\left(1-t_{i}\right)^{2}}\right. \\
& -\left(\frac{\left(\rho_{R_{i}} \sigma-\rho_{R_{j}} \delta\right)}{2\left(1-t_{i}\right)}\right)^{2} \\
& -t_{i} \frac{\left[\left(\rho_{R_{i}} \sigma-\rho_{R_{j}} \delta\right)\right]^{2}}{2\left(1-t_{i}\right)^{3}} \\
& \frac{\partial t_{i}^{*}}{\partial \rho_{M_{j}}}=-\frac{4 \delta\left(\rho_{R_{i}} \sigma-\rho_{R_{j}} \delta\right)}{\left[2\left(\rho_{M_{i}} \sigma-\rho_{M_{j}} \delta\right)+\left(\rho_{R_{i}} \sigma-\rho_{R_{j}} \delta\right)\right]^{2}}<0, \\
& \frac{\partial t_{i}^{*}}{\partial \rho_{R_{i}}}=\frac{4 \sigma\left(\delta \rho_{M_{j}}-\sigma \rho_{M_{i}}\right)}{\left[2\left(\rho_{M_{i}} \sigma-\rho_{M_{j}} \delta\right)+\left(\rho_{R_{i}} \sigma-\rho_{R_{j}} \delta\right)\right]^{2}}<0, \\
& \frac{\partial t_{i}^{*}}{\partial \rho_{R_{j}}}=\frac{4 \delta\left(\sigma \rho_{M_{i}}-\delta \rho_{M_{j}}\right)}{\left[2\left(\rho_{M_{i}} \sigma-\rho_{M_{j}} \delta\right)+\left(\rho_{R_{i}} \sigma-\rho_{R_{j}} \delta\right)\right]^{2}}>0
\end{aligned}
$$$$
-\frac{3}{4}\left(\frac{\left(\rho_{R_{i}} \sigma-\rho_{R_{j}} \delta\right)}{\left(1-t_{i}\right)}\right)^{2}
$$$$
\left.-\frac{1}{2} t_{i} \frac{\left(\rho_{R_{i}} \sigma-\rho_{R_{j}} \delta\right)^{2}}{2\left(1-t_{i}\right)^{3}}\right\}
$$$$
=\frac{1}{\left(1-t_{i}\right)}\left[\frac{\partial \pi}{\partial t_{i}}-\frac{3}{4}\left(\frac{\left(\rho_{R_{i}} \sigma-\rho_{R_{j}} \delta\right)}{\left(1-t_{i}\right)}\right)^{2}\right.
$$$$
\left.-\frac{1}{2} t_{i} \frac{\left(\rho_{R_{i}} \sigma-\rho_{R_{j}} \delta\right)^{2}}{2\left(1-t_{i}\right)^{3}}\right]
$$$$
=-\frac{1}{\left(1-t_{i}\right)}\left[\frac{3}{4}\left(\frac{\rho_{R_{i}} \sigma-\rho_{R_{j}} \delta}{\left(1-t_{i}\right)}\right)^{2}\right.
$$$$
\left.+\frac{1}{2} t_{i} \frac{\left(\rho_{R_{i}} \sigma-\rho_{R_{j}} \delta\right)^{2}}{2\left(1-t_{i}\right)^{3}}\right]<0 .
$$

$\partial^{2} \pi_{R} / \partial a_{1} \partial a_{2}=0$. It follows that function (1) is concave and the proof is complete.

Proof of Proposition 3. If $t_{i}^{*}=1-\left(2\left(\rho_{R_{i}} \sigma-\rho_{R_{j}} \delta\right) /\left(2\left(\rho_{M_{i}} \sigma-\right.\right.\right.$ $\left.\left.\left.\rho_{M_{j}} \delta\right)+\left(\rho_{R_{i}} \sigma-\rho_{R_{j}} \delta\right)\right)\right)>0,(i, j=1,2, i \neq j)$, then $2\left(\rho_{M_{i}} \sigma-\right.$ $\left.\rho_{M_{j}} \delta\right)-\left(\rho_{R_{i}} \sigma-\rho_{R_{j}} \delta\right)>0$, and $\left(\rho_{M_{j}} \sigma-\rho_{M_{i}} \delta\right) /\left(\rho_{R_{j}} \sigma-\rho_{R_{i}} \delta\right)>$ $1 / 2$. Similarly, if $t_{i}^{*}=1-\left(2\left(\rho_{R_{i}} \sigma-\rho_{R_{j}} \delta\right) /\left(2\left(\rho_{M_{i}} \sigma-\rho_{M_{j}} \delta\right)+\right.\right.$ $\left.\left.\left(\rho_{R_{i}} \sigma-\rho_{R_{j}} \delta\right)\right)\right) \geq 1 / 2$, then $2\left(\rho_{M_{i}} \sigma-\rho_{M_{j}} \delta\right)-3\left(\rho_{R_{i}} \sigma-\rho_{R_{j}} \delta\right)>0$, and $\left(\rho_{M_{j}} \sigma-\rho_{M_{i}} \delta\right) /\left(\rho_{R_{j}} \sigma-\rho_{R_{i}} \delta\right) \geq 3 / 2$. Proof of Proposition 3 is complete.

Proof of Proposition 4. From (5),

$$
\frac{\partial t_{i}^{*}}{\partial \rho_{M_{i}}}=\frac{\sigma\left(\rho_{R_{i}} \sigma-\rho_{R_{j}} \delta\right)}{\left[2\left(\rho_{M_{i}} \sigma-\rho_{M_{j}} \delta\right)+\left(\rho_{R_{i}} \sigma-\rho_{R_{j}} \delta\right)\right]^{2}}>0
$$

$(i, j=1,2, i \neq j)$,
Considering $\rho_{M_{i}} \approx \rho_{M_{j}}, \rho_{R_{i}} \approx \rho_{R_{j}},(i=i, j)$, then from (5) or (6), this study achieves that

$$
\begin{gathered}
\lim _{\substack{\rho_{M_{j}} \rightarrow \rho_{M_{i}} \\
\rho_{R_{j}} \rightarrow \rho_{R_{i}}}} \frac{\partial t_{i}^{*}}{\partial \sigma}=\frac{4 \delta\left(\rho_{M_{j}} \rho_{R_{i}}-\rho_{M_{i}} \rho_{R_{j}}\right)}{\left[2\left(\rho_{M_{i}} \sigma-\rho_{M_{j}} \delta\right)+\left(\rho_{R_{i}} \sigma-\rho_{R_{j}} \delta\right)\right]^{2}}=0, \\
\lim _{\substack{\rho_{M_{j}} \rightarrow \rho_{M_{i}} \\
\rho_{R_{j}} \rightarrow \rho_{R_{i}}}} \frac{\partial t_{i}^{*}}{\partial \delta}=\frac{4 \sigma\left(\rho_{M_{i}} \rho_{R_{j}}-\rho_{M_{j}} \rho_{R_{i}}\right)}{\left[2\left(\rho_{M_{i}} \sigma-\rho_{M_{j}} \delta\right)+\left(\rho_{R_{i}} \sigma-\rho_{R_{j}} \delta\right)\right]^{2}}=0 .
\end{gathered}
$$

Proof of Proposition 4 is complete.

Proof of Proposition 5. We have the following:

$$
\begin{aligned}
\frac{\partial a_{i}^{*}}{\partial \rho_{R_{i}}}= & \frac{1}{8} \sigma\left[2\left(\rho_{M_{i}} \sigma-\rho_{M_{j}} \delta\right)+\left(\rho_{R_{i}} \sigma-\rho_{R_{j}} \delta\right)\right]>0, \\
& (i, j=1,2, i \neq j), \\
\frac{\partial a_{i}^{*}}{\partial \rho_{R_{j}}}= & -\frac{1}{8} \delta\left[2\left(\rho_{M_{i}} \sigma-\rho_{M_{j}} \delta\right)+\left(\rho_{R_{i}} \sigma-\rho_{R_{j}} \delta\right)\right]<0, \\
\frac{\partial a_{i}^{*}}{\partial \rho_{M_{i}}}= & \frac{1}{4} \sigma\left[2\left(\rho_{M_{i}} \sigma-\rho_{M_{j}} \delta\right)+\left(\rho_{R_{i}} \sigma-\rho_{R_{j}} \delta\right)\right]>0, \\
\frac{\partial a_{i}^{*}}{\partial \rho_{M_{j}}}= & -\frac{1}{4} \delta\left[2\left(\rho_{M_{i}} \sigma-\rho_{M_{j}} \delta\right)+\left(\rho_{R_{i}} \sigma-\rho_{R_{j}} \delta\right)\right]<0, \\
\frac{\partial a_{i}^{*}}{\partial \sigma}= & \frac{1}{8}\left[2\left(\rho_{M_{i}} \sigma-\rho_{M_{j}} \delta\right)+\left(\rho_{R_{i}} \sigma-\rho_{R_{j}} \delta\right)\right] \\
& \times\left(2 \rho_{M_{i}}+\rho_{R_{i}}\right)>0 .
\end{aligned}
$$

By differentiating (3) with respect to $t_{i}$, we achieve

$$
\frac{\partial a_{i}^{*}}{t_{i}}=\frac{\left(\rho_{R_{i}} \sigma-\rho_{R_{j}} \delta\right)^{2}}{2\left(1-t_{i}\right)^{3}}>0 .
$$

Proof of Proposition 5 is complete. 
Proof of Proposition 7. For $i, j=1,2$ and $i \neq j$,

$$
\begin{aligned}
\pi_{M}^{B}= & \rho_{M_{i}}\left(z+\sigma \sqrt{a_{i}}-\delta \sqrt{a_{j}}\right)+\rho_{M_{j}}\left(z+\sigma \sqrt{a_{j}}-\delta \sqrt{a_{i}}\right) \\
& -t_{i} a_{i}-t_{j} a_{j},
\end{aligned}
$$$$
\pi_{M}^{S}=\rho_{M_{i}}\left(z+\sigma \sqrt{a_{i}}\right)+\rho_{M_{j}}\left(z-\delta \sqrt{a_{i}}\right)-t_{i} a_{i},
$$

$$
\pi_{M}^{N}=\rho_{M_{i}} z+\rho_{M_{j}} z \text {. }
$$

If $\rho_{M_{i}} \approx \rho_{M_{j}}=\rho_{M}, \rho_{R_{i}} \approx \rho_{R_{j}}=\rho_{R}, \rho_{M} / \rho_{R}>1 / 2, \rho_{M} / \rho_{R}>$ $1 / 2$, by (A.10)-(A.11), we get

$$
\begin{aligned}
\pi_{M}^{B}-\pi_{M}^{S}= & -\rho_{M_{i}} \delta \sqrt{a_{j}}+\rho_{M_{j}} \sigma \sqrt{a_{j}}-t_{j} a_{j} \\
= & \frac{\rho_{M}\left[2\left(\rho_{M_{j}} \sigma-\rho_{M_{i}} \delta\right)+\left(\rho_{R_{j}} \sigma-\rho_{R_{i}} \delta\right)\right]}{4}(\sigma-\delta) \\
& -\left(\left(\left[2\left(\rho_{M_{j}} \sigma-\rho_{M_{i}} \delta\right)+\left(\rho_{R_{j}} \sigma-\rho_{R_{i}} \delta\right)\right]\right.\right. \\
& \left.\times\left[2\left(\rho_{M_{j}} \sigma-\rho_{M_{i}} \delta\right)-\left(\rho_{R_{j}} \sigma-\rho_{R_{i}} \delta\right)\right]\right) \\
& \left.\times(16)^{-1}\right) \\
= & \left(\frac{\left(\rho_{M}\right)^{2}}{4}+\frac{\rho_{M} \rho_{R}}{4}-\frac{\left(\rho_{R}\right)^{2}}{16}\right)(\sigma-\delta)^{2}>0 .
\end{aligned}
$$

By (A.11)-(A.12), we have

$$
\begin{aligned}
\pi_{M}^{S}-\pi_{M}^{N}= & \sigma \rho_{M_{i}} \sqrt{a_{i}}-\delta \rho_{M_{j}} \sqrt{a_{i}}-t_{i} a_{i} \\
= & \frac{\rho_{M}\left[2\left(\rho_{M_{i}} \sigma-\rho_{M_{j}} \delta\right)+\left(\rho_{R_{i}} \sigma-\rho_{R_{j}} \delta\right)\right]}{4}(\sigma-\delta) \\
& -\left(\left(\left[2\left(\rho_{M_{i}} \sigma-\rho_{M_{j}} \delta\right)+\left(\rho_{R_{i}} \sigma-\rho_{R_{j}} \delta\right)\right]\right.\right. \\
& \left.\times\left[2\left(\rho_{M_{i}} \sigma-\rho_{M_{j}} \delta\right)-\left(\rho_{R_{i}} \sigma-\rho_{R_{j}} \delta\right)\right]\right) \\
& \left.\times(16)^{-1}\right) \\
= & \left(\frac{\left(\rho_{M}\right)^{2}}{4}+\frac{\rho_{M} \rho_{R}}{4}-\frac{\left(\rho_{R}\right)^{2}}{16}\right)(\sigma-\delta)^{2}>0 .
\end{aligned}
$$

And, by (A.10)-(A.12), we achieve

$$
\begin{aligned}
\pi_{M}^{B}-\pi_{M}^{N}= & \rho_{M_{i}}\left(\sigma \sqrt{a_{i}}-\delta \sqrt{a_{j}}\right)+\rho_{M_{j}}\left(\sigma \sqrt{a_{j}}-\delta \sqrt{a_{i}}\right) \\
& -t_{i} a_{i}-t_{j} a_{j} \\
= & \frac{1}{2} \rho_{M}\left(2 \rho_{M}+\rho_{R}\right)(\sigma-\delta)^{2} \\
& -\frac{2 \rho_{M}-\rho_{R}}{16 \rho_{M}+8 \rho_{R}}\left[\left(2 \rho_{M}+\rho_{R}\right)(\sigma-\delta)\right]^{2} \\
= & \frac{1}{8}\left(2 \rho_{M}+\rho_{R}\right)(\sigma-\delta)^{2}\left(2 \rho_{M}-\rho_{R}\right)>0 .
\end{aligned}
$$

So $\pi_{M}^{B}>\pi_{M}^{S}>\pi_{M}^{N}$. For the same reason, we have $\pi_{R}^{B}>\pi_{R}^{S}>$ $\pi_{R}^{N}$.

Proof of Proposition 7 is complete.

Proof of Proposition 8. If $\rho_{M_{i}} \approx \rho_{M_{j}}, \rho_{R_{i}} \approx \rho_{R_{j}},(i, j=1,2$, $i \neq j) \sigma>\delta$, then we have

$$
\begin{aligned}
& \overline{a_{i}}-a_{i}^{*}=\frac{1}{4}\left[\left(\rho_{M_{i}}+\rho_{R_{i}}\right) \sigma-\left(\rho_{M_{j}}+\rho_{R_{j}}\right) \delta\right]^{2} \\
&-\frac{1}{16}\left[2\left(\rho_{M_{i}} \sigma-\rho_{M_{j}} \delta\right)+\left(\rho_{R_{i}} \sigma-\rho_{R_{j}} \delta\right)\right]^{2} \\
&=\frac{1}{16}\left[\left(4 \rho_{M_{j}}+3 \rho_{R_{j}}\right) \sigma-\left(4 \rho_{M_{i}}+2 \rho_{R_{i}}\right) \delta\right] \\
& \times\left(\rho_{R_{j}} \sigma-\rho_{R_{i}} \delta\right)>0, \\
& \bar{\Pi}-\Pi^{*}=\left(\rho_{M_{i}}+\rho_{R_{i}}\right)\left(z+\sigma \sqrt{\bar{a}_{i}}-\delta \sqrt{\bar{a}_{j}}\right) \\
&+\left(\rho_{M_{j}}+\rho_{R_{j}}\right)\left(z+\sigma \sqrt{\bar{a}_{j}}-\delta \sqrt{\bar{a}_{i}}\right)-\overline{a_{i}}-\overline{a_{j}} \\
& \quad-\left(\rho_{M_{i}}+\rho_{R_{i}}\right)\left(z+\sigma \sqrt{a_{i}^{*}}-\delta \sqrt{a_{j}^{*}}\right) \\
&-\left(\rho_{M_{j}}+\rho_{R_{j}}\right) \\
& \quad \times\left(z+\sigma \sqrt{a_{j}^{*}}-\delta \sqrt{a_{i}^{*}}\right)+a_{i}^{*}+a_{j}^{*} \\
& \approx 4 \rho_{R}\left(\rho_{M}+\rho_{R}\right)\left(\sqrt{\bar{a}_{i}}-\sqrt{a_{i}^{*}}\right)-2\left(\overline{a_{i}}-a_{i}^{*}\right) \\
&= \rho_{R}\left(\rho_{M}+\rho_{R}\right)(\sigma-\delta)^{2}-\frac{1}{8} \\
& \times\left[\left(4 \rho_{M}+3 \rho_{R}\right) \sigma-\left(4 \rho_{M}+2 \rho_{R}\right)\right] \rho_{R}(\sigma-\delta) \\
&>\left.\left(\rho_{M}+\rho_{R}\right)-\frac{1}{8}\left(4 \rho_{M}+3 \rho_{R}\right)\right] \rho_{R} \\
& \times(\sigma-\delta)^{2}>0 .
\end{aligned}
$$

Proof of Proposition 8 is complete. 


\section{Acknowledgments}

This work was supported by the National Social Science Foundation of China (11BGL034) and the Soft Science Foundation of Guangdong Province of China (2012B070300046). Sincere thanks are offered to the anonymous reviewers for their helpful suggestions.

\section{References}

[1] J. V. Durme, R. J. Brodie, and D. Redmore, "Brand equity in cooperative business relationships: exploring the development of a conceptual model," Marketing Theory, vol. 3, no. 1, pp. 37-57, 2003.

[2] S. Jørgensen, S. P. Sigué, and G. Zaccour, "Dynamic cooperative advertising in a channel," Journal of Retailing, vol. 76, no. 1, pp. 71-92, 2000.

[3] J. Xie and J. C. Wei, "Coordinating advertising and pricing in a manufacturer-retailer channel," European Journal of Operational Research, vol. 197, no. 2, pp. 785-791, 2009.

[4] Z. Huang and S. X. Li, "Co-op advertising models in manufacturer-retailer supply chains: a game theory approach," European Journal of Operational Research, vol. 135, no. 3, pp. 527-544, 2001.

[5] Z. Huang, S. X. Li, and V. Mahajan, "An analysis of manufacturer-retailer supply chain coordination in cooperative advertising," Decision Sciences, vol. 33, no. 3, pp. 469-494, 2002.

[6] M. G. Nagler, "An exploratory analysis of the determinants of cooperative advertising participation rates," Marketing Letters, vol. 17, no. 2, pp. 91-102, 2006.

[7] K. Sen, "Advertising fees in the franchised channel," in Franchising: Contemporary Issues and Research, P. J. Kaufmann and R. P. Dant, Eds., The Haworth Press, New York, NY, USA, 1994.

[8] R. P. Dant and P. D. Berger, "Modelling cooperative advertising decisions in franchising," Journal of the Operational Research Society, vol. 47, no. 9, pp. 1120-1136, 1996.

[9] P. D. Berger, "Vertical cooperative advertising ventures," Journal of Marketing Research, vol. 9, no. 3, pp. 309-312, 1972.

[10] L. Brennan, "How retailers are putting it all together," Sales and Marketing Management, vol. 5, pp. 62-65, 1988.

[11] M. Bergen and G. John, "Understanding cooperative advertising participation rates in conventional channels," Journal of Marketing Research, vol. 34, no. 3, pp. 357-369, 1997.

[12] S. Karray and G. Zaccour, "Could co-op advertising be a manufacturer's counterstrategy to store brands?" Journal of Business Research, vol. 59, no. 9, pp. 1008-1015, 2006.

[13] R. Yan, "Cooperative advertising, pricing strategy and firm performance in the e-marketing age," Journal of the Academy of Marketing Science, vol. 38, no. 4, pp. 510-519, 2010.

[14] S.-D. Wang, Y.-W. Zhou, J. Min, and Y.-G. Zhong, "Coordination of cooperative advertising models in a one-manufacturer two-retailer supply chain system," Computers \& Industrial Engineering, vol. 61, no. 4, pp. 1053-1071, 2011.

[15] J. Zhang and J. Xie, "A game theoretical study of cooperative advertising with multiple retailers in a distribution channel," Journal of Systems Science and Systems Engineering, vol. 21, no. 1, pp. 37-55, 2012.

[16] J. Yue, J. Austin, M.-C. Wang, and Z. Huang, "Coordination of cooperative advertising in a two-level supply chain when manufacturer offers discount," European Journal of Operational Research, vol. 168, no. 1, pp. 65-85, 2006.
[17] X. He, A. Krishnamoorthy, A. Prasad, and S. P. Sethi, "Retail competition and cooperative advertising," Operations Research Letters, vol. 39, no. 1, pp. 11-16, 2011.

[18] B. Viscolani, "Pure-strategy Nash equilibria in an advertising game with interference," European Journal of Operational Research, vol. 216, no. 3, pp. 605-612, 2012.

[19] P. K. Chintagunta and D. Jain, "A dynamic model of channel member strategies for marketing expenditures," Marketing Science, vol. 11, no. 2, pp. 168-188, 1992.

[20] S. Jørgensen, S. Taboubi, and G. Zaccour, "Cooperative advertising in a marketing channel," Journal of Optimization Theory and Applications, vol. 110, no. 1, pp. 145-158, 2001.

[21] M. Nerlove and K. J. Arrow, "Optimal advertising policy under dynamic conditions," Economica, vol. 39, pp. 129-142, 1962.

[22] J. M. Alston, J. W. Freebairn, and J. S. James, "Beggar-thyneighbor advertising: theory and application to generic commodity promotion programs," American Journal of Agricultural Economics, vol. 83, no. 4, pp. 888-902, 2001.

[23] J. Xie and A. Neyret, "Co-op advertising and pricing models in manufacturer-retailer supply chains," Computers \& Industrial Engineering, vol. 56, no. 4, pp. 1375-1385, 2009.

[24] X. He, A. Prasad, and S. P. Sethi, "Cooperative advertising and pricing in a dynamic stochastic supply chain: feedback stackelberg strategies," Production and Operations Management, vol. 18, no. 1, pp. 78-94, 2009. 


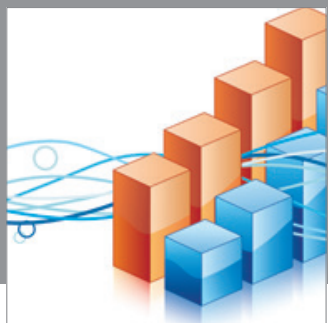

Advances in

Operations Research

mansans

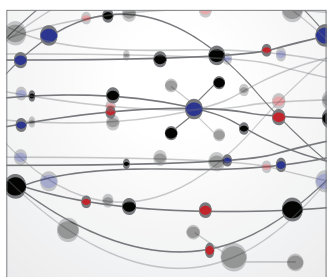

The Scientific World Journal
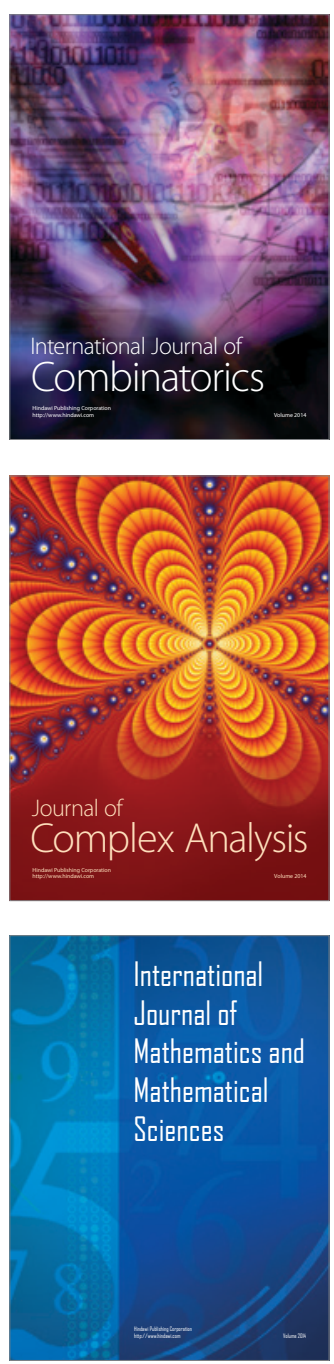
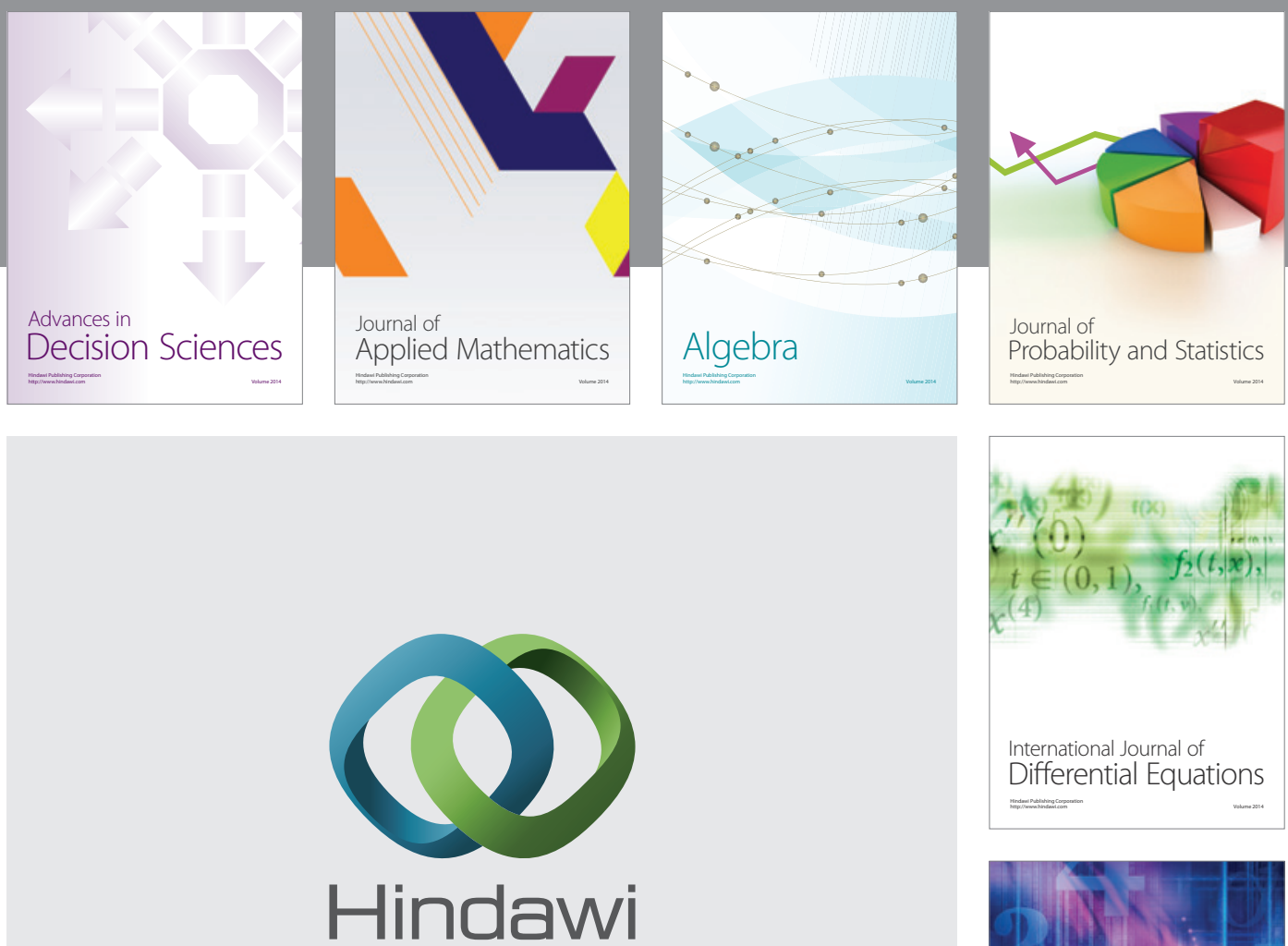

Submit your manuscripts at http://www.hindawi.com
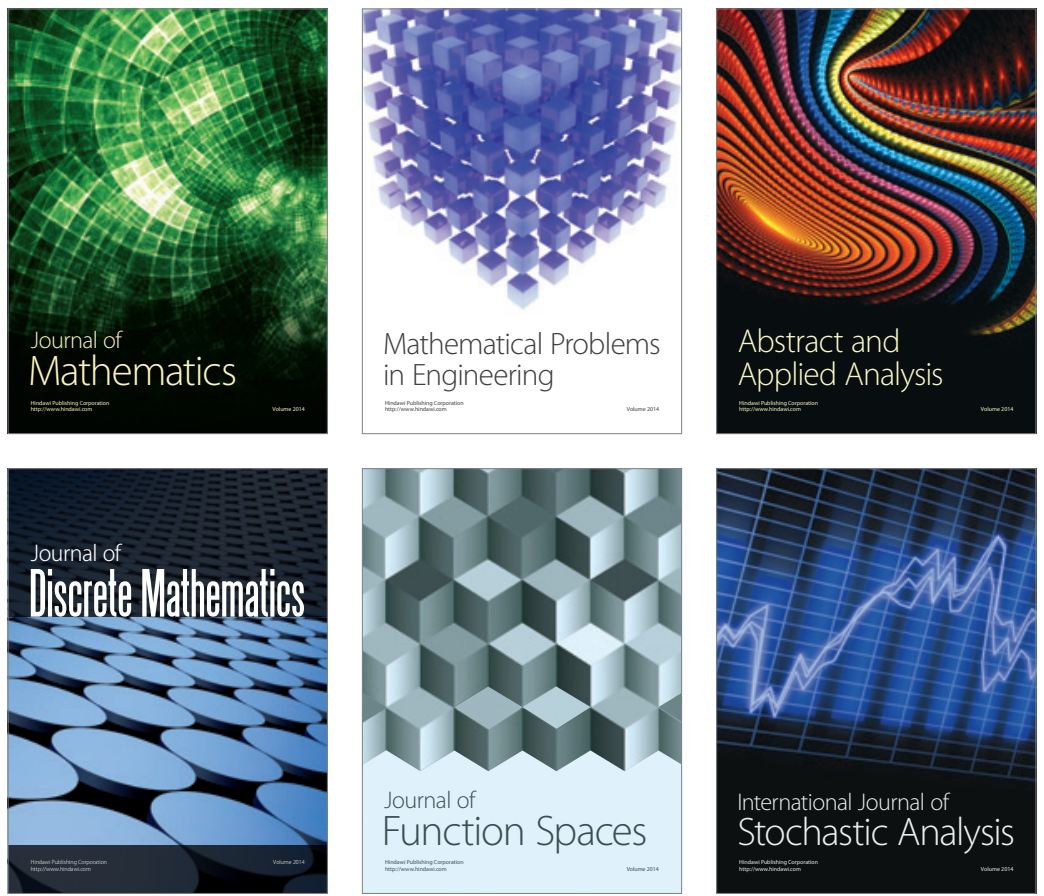

Journal of

Function Spaces

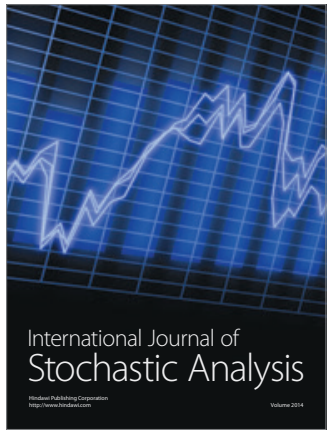

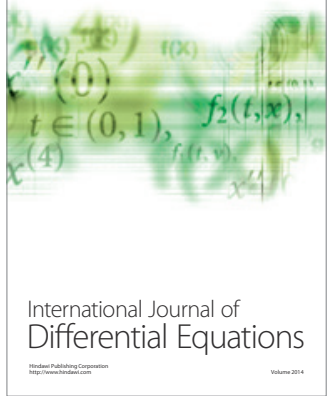
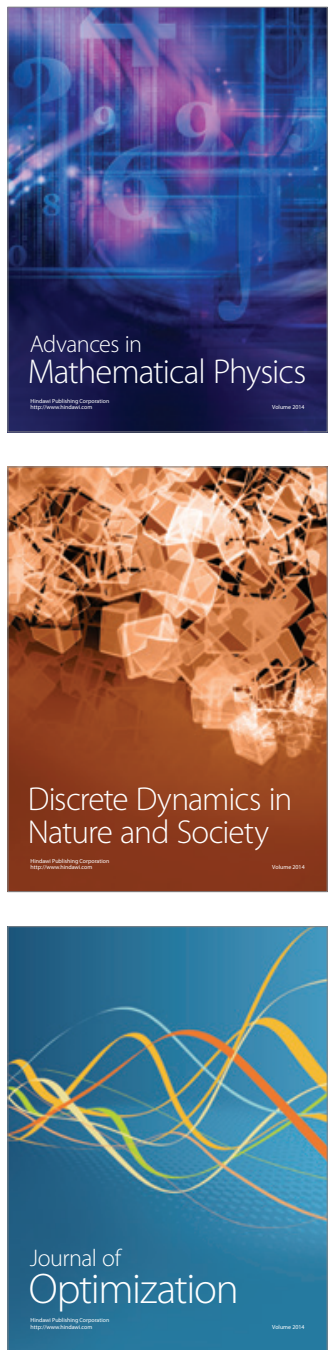